\title{
A colorful approach to teaching optics
}

\section{Nancy Magnani, Judith Donnelly}

Nancy J. Magnani, Judith Donnelly, "A colorful approach to teaching optics," Proc. SPIE 9188, Optics Education and Outreach III, 91880L (15 September 2014); doi: 10.1117/12.2060199

EDIE Event: SPIE Optical Engineering + Applications, 2014, San Diego, California, United States 


\title{
A Colorful Approach to Teaching Optics \\ Nancy J. Magnani ${ }^{\mathrm{a}}$, Judith Donnelly ${ }^{\mathrm{b}}$ \\ ${ }^{a}$ EASTCONN, 376 Hartford Turnpike, Hampton, CT 06247; ${ }^{\text {36 }} 36$ Sycamore Terrace, Windham, CT \\ 06280
}

\begin{abstract}
In a traditional Connecticut elementary school setting, the classroom teacher will teach language arts, social studies and science curriculum. For $5^{\text {th }}$ grade, the science curriculum includes learning about the senses and moon phases, in addition to the fundamentals of light. For art, music and physical education, students are sent to teachers who have certifications in teaching these subjects. In support of the science curriculum, we have traditionally provided workshops to enhance and supplement existing science curriculum. This method of instruction has become a routine. What if we invigorate the curriculum by using visual art to teach science? Will the students achieve a greater understanding of the principals of light? In this paper, we will explore the use of art to enhance the understanding of color and light phenomena.
\end{abstract}

Keywords: Connecticut Science Standards, Josef Albers, spectroscopy, reflection, refraction, laser engraving, polarization, kaleidoscopes, SPIE student chapter

\section{INTRODUCTION}

In the traditional Connecticut elementary classroom setting, the teacher teaches it "all," including science. This includes the fundamentals of light detailed in both the Connecticut (CT) state science standards and the newly published Next Generation Science Standards (NGSS). At this time, some districts in Connecticut are using the existing CT standards, some are making the transition to the NGSS and some are just waiting to see what happens. In the transition to the NGSS, there will be some shifts in curriculum, for example light and the senses will transfer to $1^{\text {st }}$ grade and it also integrates engineering thinking.

However, in support of the existing science curriculum, we have partnered for many years to provide interesting and intriguing optics based workshops for students from 10-12 years old and will continue to do so. This partnership includes support from the Three Rivers Community College SPIE student chapter. A sampling of past workshops have included: introducing the light spectrum by making and taking spectroscopes; understanding reflection by making a kaleidoscope; laser target shoot, and gelatin optics to learn the principals of refraction. Though always appreciated by the teachers and enjoyed by the students, these lessons have become routine. What can be done to introduce a new approach to teaching the principals of light and photonics to young children?

For the 2013-2014 school year, we decided on a new approach and this is using the visual arts to enhance the science curriculum. Richard Frazier writes, "Because design, problem solving, experience and familiarity with phenomena, and creative expression are indispensable aspects of art, it makes sense to consider the integration of art into the broader view of science." ${ }^{\prime 1}$ With program support from the EASTCONN Interdistrict grant Making Waves: Optics and Acoustics, student learning about light and sound will be supplemented by hands-on applications in art and music. Making Waves: Optics and Acoustics also provides a diverse group of students from the northeast region of Connecticut, who will benefit from our programs. We were somewhat surprised by increasing enrollments for this year and our task would be how to fulfill our educational mission and serve $1505^{\text {th }}$ graders, from diverse districts and backgrounds. In addition, four of the six participating teachers were, though veteran teachers, new to our program. In this paper we will specifically look at the art and light applications and lessons that we used.

*nmagnani@eastconn.org; phone 1860 455-1536; fax 1860 455-0689; eastconn.org

Optics Education and Outreach III, edited by G. Groot Gregory, Proc. of SPIE Vol. 9188,

91880L (c) 2014 SPIE · CCC code: 0277-786X/14/\$18 · doi: 10.1117/12.2060199 


\section{INTRODUCING THE PROGRAM TO TEACHERS AND STUDENTS}

A baseline knowledge of what students know about light and color is determined with a content presurvey given to the students at the beginning of the school year and before the students have had any lessons in the content area. The survey questions and number of students responding to each question is in Table 1 .

Table 1. Making Waves: Optics and Acoustics student content presurvey

\begin{tabular}{|l|c|c|c|}
\hline & $\begin{array}{c}\text { I am not } \\
\text { sure }\end{array}$ & No Yes \\
\hline $\begin{array}{l}\text { Can you identify the difference between a concave mirror and a convex } \\
\text { mirror? }\end{array}$ & 62 & 31 & 52 \\
\hline $\begin{array}{l}\text { I understand that "white" light is made up of the colors called the } \\
\text { "spectrum of light." }\end{array}$ & 39 & 46 \\
\hline Do you know what the "law of reflection" is? & 47 & 36 \\
\hline I understand that the high or low pitch of a sound depends on vibration. & 22 & 14 & 101 \\
\hline
\end{tabular}

\subsection{Evaluating the results of the survey}

The results of the survey at first glance appear to be consistent, though not all classes completed the survey. Pitch is also taught through the music programs so it would be expected that most students would understand this principal. Because of scheduling, some classes had already started their curriculum units on light and the senses. Assuming that most classes are 20-25 students, two classes appear to understand lessons in white light and reflection. However, the "law of reflection" is not taught as part of the curriculum so this indicates the students do not know what they think they know. Though in practice, these results should guide our workshops for the year, in reality, the workshops were planned because of the large number of students, availability of qualified workshop instructors and space.

\subsection{Teaching to large groups of students}

Though our preference is to teach to small groups of students (20-25 is ideal), realistically this is not possible. Because we are accommodating three schools, each from a different district, they have different calendars and this past winter was particularly difficult with large amounts of snow affecting school calendars. In addition, we want students to reinforce their learning by taking "something" home from the workshops to show their families. The cost of the materials must be calculated and kept within reason. In planning a workshop of 45-50 minutes the amount of time involved in handing out materials must also be considered.

We provided the students with bright orange t-shirts with the financial sponsors' names on the back and Jr Laser Camp on the front. The teachers appreciated this because they could easily spot their students on the large campus settings and when our program was at O'Connell, could easily identify the students participating in our program. 


\subsection{Planning the workshops for the year}

The plan for the 2013-2014 school year would include three class meetings of all 150 students (refer to Figure 1) attending each class meeting and closing with Jr Laser Camp: the first at Central Connecticut State University (CCSU), the second hosted by one of the participating elementary schools, O'Connell, and the last meeting, Jr. Laser Camp, at Three Rivers Community College. In addition, there would be lessons in the classroom in between the large gatherings and in closing a post-content survey would be provided to assess what the students had learned. Workshops at each of the class meetings would include the integration of either art or music with a science lesson. An ambitious plan, indeed.
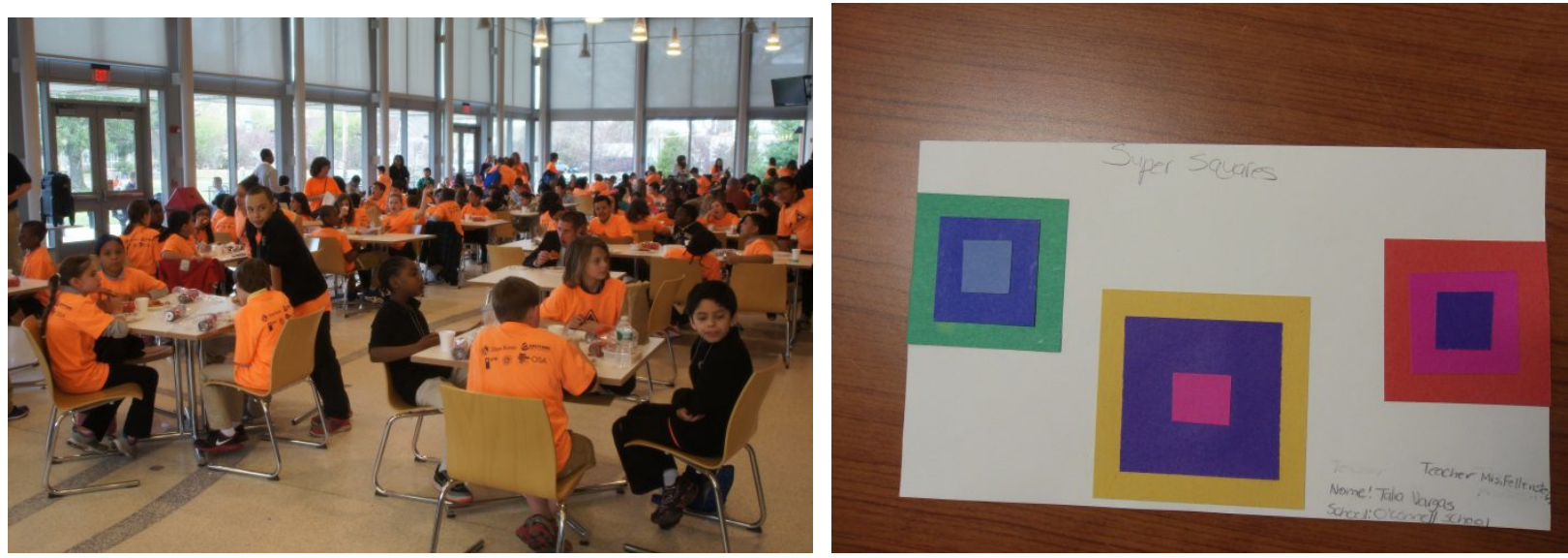

Figure 1. On the left 170 students gather for lunch at TRCC. On the right, example of student "homage to a square" artwork.

\subsection{Introducing the first lesson: "What Color is a...?"}

We decided to introduce ourselves to the students with an individual class lesson about color and how it is perceived. Included with this lesson, students read the book Hello, Red Fox, by Eric Carle. ${ }^{3}$

The hands-on portion of the lesson would be "What Color is a...?" chosen from the PHOTON II projects' Explorations in Optics. ${ }^{2}$ In this lesson, students answer the question, can your eyes be fooled by the color of a light source? A tomato is red under "white light," but is it a red tomato if a blue LED light illuminates the tomato in a dark room? Our students were more interested in guessing the object rather than telling us what color they saw when the tomato was illuminated under blue light (blackish). The next object was a lime, which they did saw was black but again wanted to guess the object (which they predicted was an avocado).

The students were excited about this lesson, though not very interested in the details. They did have many questions about lighting in stores and did see the connection. The other purpose of this lesson was to meet the students and introduce the lessons for the year and this was accomplished.

\section{FALL STUDENT MEETING AT CENTRAL CONNECTICUT STATE UNIVERSITY}

For this meeting in the fall of 2013, the students were excited because for many, it was their first visit to a university campus. Some were more interested in going to the "gift shop" (book store) than participating in three workshops. Even on a large campus, which was in-session, it is difficult to find space for this many students. The students were divided into three groups of 70-75 students each and rotated between each workshop. We were provided with a large conference area for the optics workshop, which was "make and take" spectroscopes. For the other two workshops, students attended a planetarium show and participated in a dance workshop. The dance workshop represented the integration of art into the science. The performing artist introduced dance moves that imitated waves. Students used their new dance moves to demonstrate sound waves. One student commented, "I enjoyed it because I learned how sound waves moved. It was really interesting the way we weaved through each other. 


\section{1 "Make and take" spectroscopes}

This is another workshop taken from the PHOTON II Explorations in Optics. ${ }^{2}$ We have presented this many times but to a smaller audience and we were concerned how to adapt the lesson so that the students would understand the content. Other concerns included: how to hand out materials to all the students, how to present the lesson and meet the time limit of 45 minutes. Nonetheless, nearly every student at least reported seeing the "rainbows" and was able to correctly name the type of light producing the "mystery spectra" at the end of the lesson. This understanding is demonstrated in the hand drawn thank you postcards made by the students (refer to Figure 2).
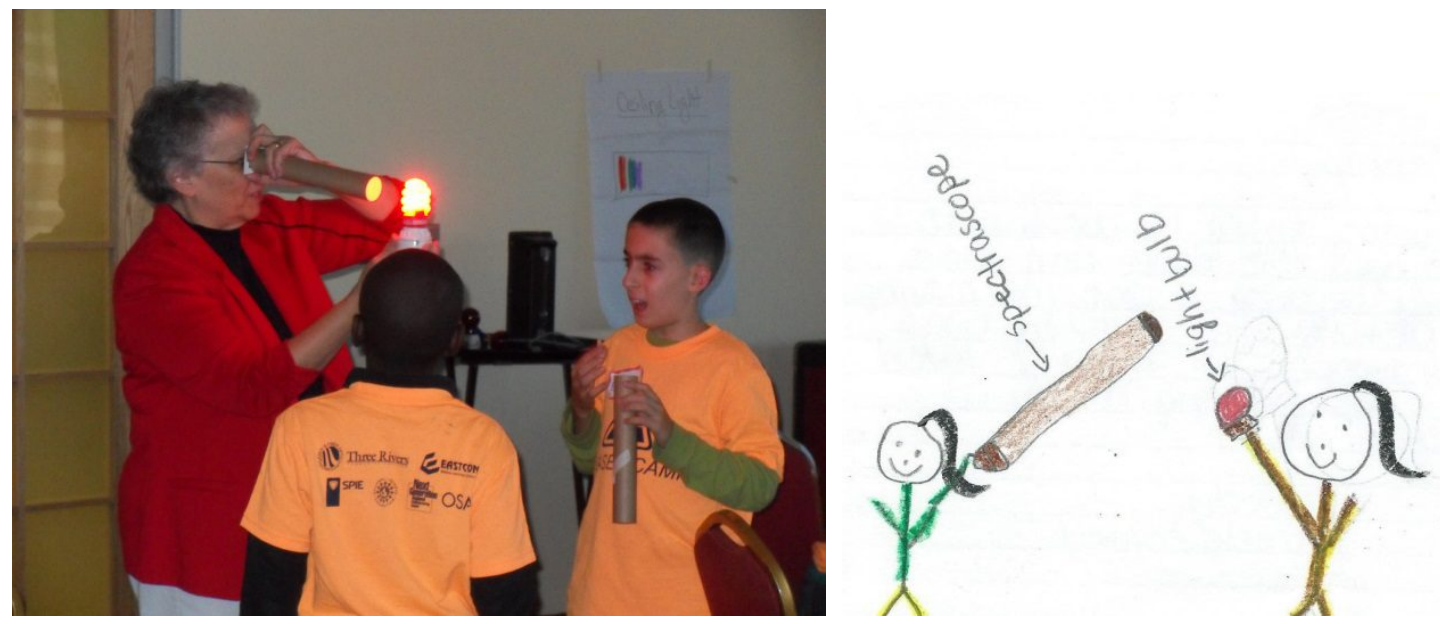

Figure 2. On the left, Judy Donnelly with students testing their spectroscopes. On the right, student 'exit card' drawing demonstrating what they learned about spectroscopes.

\section{WINTER STUDENT MEETING AT O'CONNELL SCHOOL}

For this second meeting, visual arts and music was the theme. The event opened with the Hartford Jazz Ensemble performing for the students and talking about sound and their individual instruments. Space was limited so the visual arts workshops needed to be "presenter friendly" (i.e. for presenters with no background in art or optics) and because we did not have enough classroom space, there would be larger number of students (25-30) in each workshop. There would be two workshops: the first exploring color through the work of Josef Albers and the second using a still life painting to explain refraction.

\subsection{The artwork of Josef Albers}

The emphasis of this workshop was for the students to continue their exploration of color and how it can be perceived. In this case, the students were developing an understanding of how colors interact with each other. Teachers were provided with Josef Albers' book Interaction of Color and a student book An Eye for Color by Natasha Wing. Josef Albers reduced form to its simplest: a square of color. He then studied what happened visually when placing different colored squares together. Albers said 'I'm not paying 'homage to a square'. It's only the dish I serve my craziness about color in."

With this inspiration, students practiced combining red squares, subtracting and adding colors, dull and dancing squares and then created their own "homage to a square in the style of Josef Albers" (refer to Figure 3). This artwork would be on display in a gallery walk at Jr Laser Camp (refer to Figure 1).

\subsection{Using still life painting to demonstrate refraction}

For this lesson, the students were presented with a still life and instructed to use any of the art supplies available (colored pencil, water colors or markers) to sketch and color their representation of the still life (refer to Figure 3). They were 
then instructed to label this as "Still Life \#1." For the students who had some background in the study of light, they might have realized this was a lesson in refraction. For others, they were painting a picture of paint brushes in a jar.

At this point, the students stopped their work and were given a lesson in refraction. They were shown famous artwork that demonstrated refraction and asked to look more closely at their own work. They were then given the opportunity to create "Still Life \#2" in which they looked more closely at the still life and included the refraction elements.
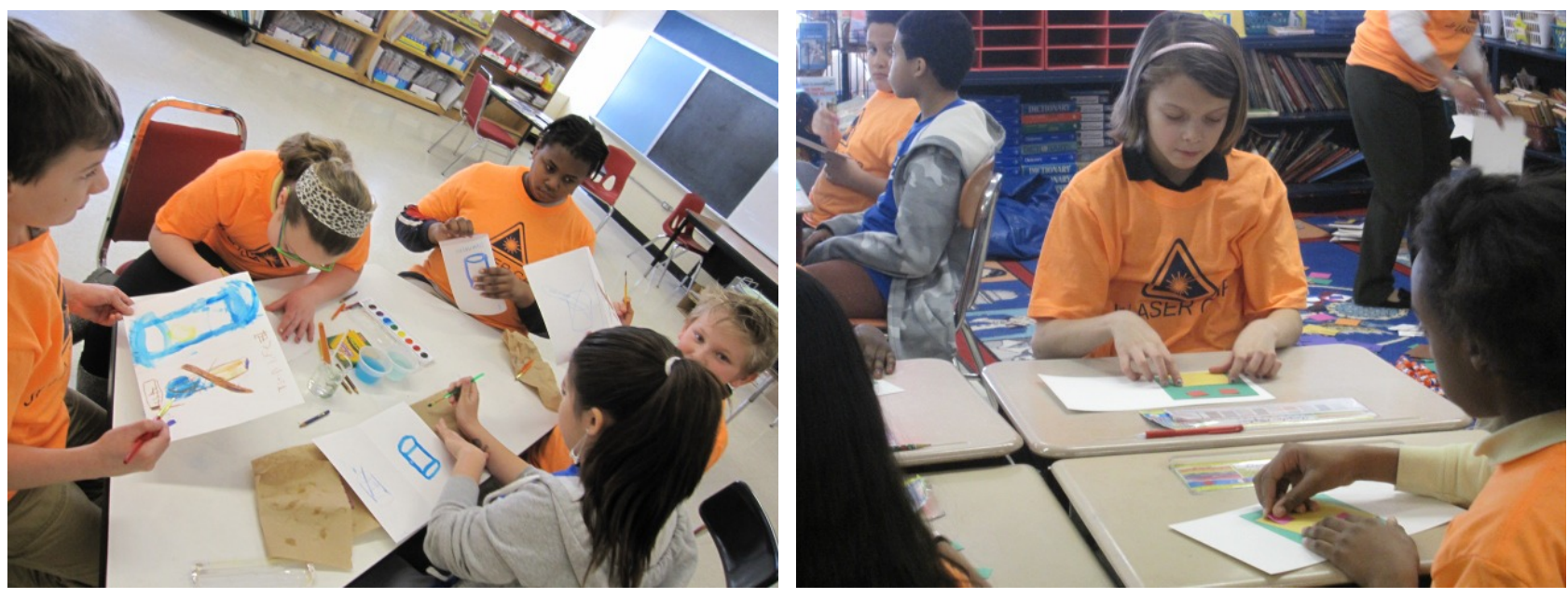

Figure 3. On left, students creating refraction artwork. On right, students creating 'homage to a square in the style of Josef Albers.'

\section{JR. LASER CAMP AT THREE RIVERS COMMUNITY COLLEGE}

We have presented $J r$. Laser Camp as the culminating event for $5^{\text {th }}$ graders for several years. However, this was the largest $J r$. Laser Camp. We accommodated an additional 20 students for a total of 170, and served a pizza lunch, too, through funding from the Regional Center for Next Generation Manufacturing (RCNGM). To accommodate this number of students, we presented a large workshop of "make and take" kaleidoscopes and six smaller workshops with a maximum of 15 students in each workshop. With the art theme, we offered workshops that normally we have used only with high school students: pinhole photography and polarized light art and also included balloon cars, river quality, going to college, laser engraving and concluded the day with a laser light show, presented by SPIE visiting lecturer Sean Kearney, The Laser Guy.

Without the support of the SPIE student chapter helping with workshop preparations, leading workshops and serving pizza, this would not have been the successful day that it was for all.

\subsection{Make and Take Kaleidoscopes}

The larger lesson is about reflection, but the art piece comes in with the "jewels" in the end cap of the kaleidoscope. Because this workshop was given to 70 students in one session, much of the time was spent in making the kaleidoscope and not in the lesson of reflection. On display was the "giant kaleidoscope" in which the students saw multiple images of themselves. However, the students enjoyed making the kaleidoscopes (refer to Figure 4). 

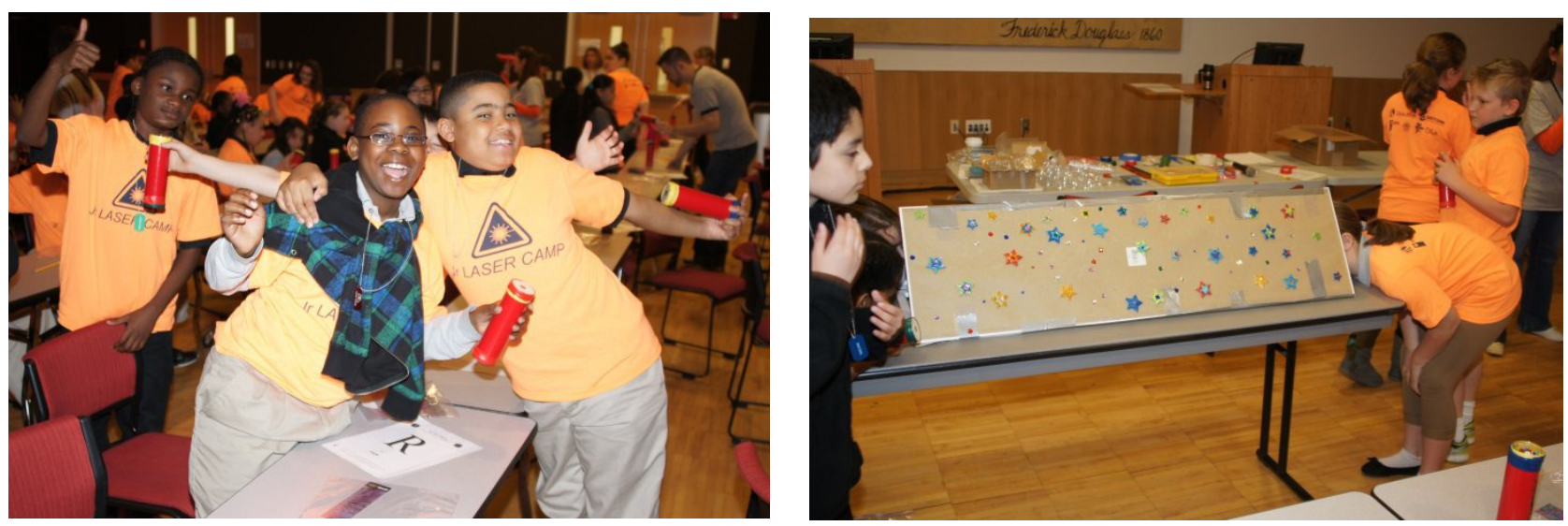

Figure 4. On left, students with kaleidoscopes. On right, students with 'giant kaleidoscope.'

\subsection{Pinhole photography}

This lesson and take home project was developed and taught by the Three Rivers students. The complexity of why a pinhole camera works was beyond the understanding of this group of $5^{\text {th }}$ graders and the cameras were pre-made and the film loaded before students arrived. However, they were amazed by the results and enjoyed the process more than high school students. They liked that they were able to do something "out of the ordinary" and would like to take more photographs so they could improve the quality and "take it up a notch." While the photos were being developed, students made bracelets of UV color changing beads and were reminded of the importance of sunscreen.

\subsection{Polarized light art}

Students first experimented with a $10 \mathrm{~cm}$ square of polarizing film mounted in cardboard frames, noticing the extinction of reflections from the floor and whiteboard. With a partner, they then experimented with parallel and perpendicular transmission axes. Polarization was (crudely) explained with the help of two oven racks. To create amazing "art", students used cellophane tape to attach laser-cut cellophane shapes to the square polarizer, viewing the result through a smaller circle of laminated polarizing film (refer to Figure 5).
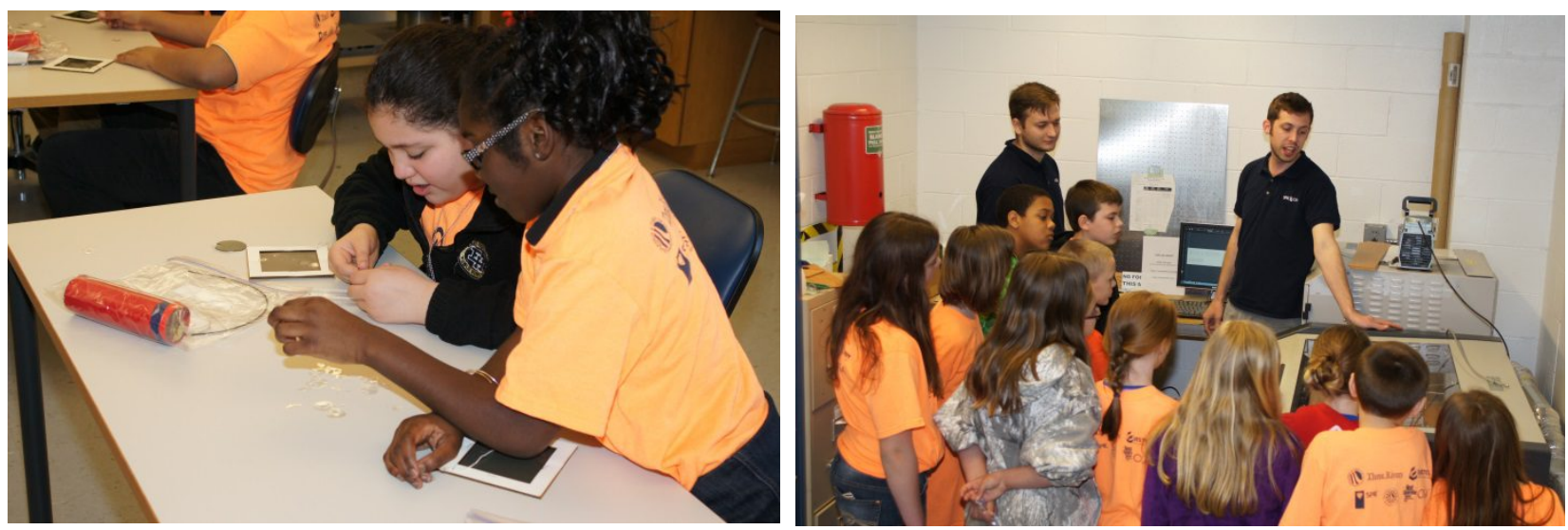

Figure 5. On left, students creating polarized light art. On right, students with SPIE student chapter students demonstrating the laser engraver.

\subsection{Laser engraving}

Three Rivers students explained the process of engraving and cutting, paying special attention to the mirrors that direct the beam onto the work piece (refer to Figure 5). Each student was allowed to choose one of four graphics and watch as 
the graphics were engraved and then the wood piece was cut to form an oval key tag. Because the process is slow, students were also introduced to 3D printing and other projects in the TRCC Manufacturing Lab. Once the key tags were complete, students were shown how to fill-paint the engraving.

\section{CONCLUSIONS}

We successfully introduced the visual arts into optics and photonics to 150 students. For year-end surveys, exit cards are often used to evaluate the success of workshops. In this case, students were asked to think about all the workshops for the year and then: 1)write comments about the workshop they liked the best and what they learned in that workshop 2)which workshop needed improvement and why 3) which was the "must do" workshop for next year. In year-end meetings with teachers, it does not appear that enrollments will be less for the 2014-2015 school year. Knowing that, we asked the teachers the same questions. Students and teachers agreed if they had to choose one work shop to continue next year, they all said "the laser light show with Sean!"

Though the laser light show was not just entertainment, one student wrote, "my absolute favorite activity was the laser light show because it was interesting how he explained how the machine worked, how the colors go together to make different colors and then we actually watched the laser light show." By using comments from students, teachers and workshop facilitators, we have evaluated what worked, what did not work and what needs to change for next year.

\subsection{Lessons that did not work or need revising}

Sometimes lessons do not work because of the organization or materials rather than the content. This is what happened for the still life lesson, homage to a square and kaleidoscopes.

For homage to a square, it was lack of skilled presenters and they did not thoroughly prepare themselves for the lesson content. "Squares was my favorite because it was artistic and I love art plus I get to be different and make it my own" said one student. For all of these lessons, because of time limitations and the number of students providing and distributing supplies was an issue. For that reason, students commented, "I think the kaleidoscopes were fine and when we were done they were very cool but other people kept asking for tape and that was annoying." Lack of materials also affected the refraction workshop. Though the teachers liked the concept of the workshop, they thought each student should have their own paint set.

\subsection{Lessons that worked}

Our new $J r$ Laser Camp workshops, pinhole photography and polarized light art, were well received. About pinhole photography students wrote, "My favorite was pinholes because I think it's really cool that you can take a picture without electronic devices" and "I liked the pinholes because I got to do something out of the ordinary." Polarization was a favorite for another student "the polarized light art was my favorite because I understand it and we got to take it home."

We are always trying to improve workshops and with spectroscopes, we have again improved the quality of the workshop. Though the content and lesson worked very well, it is the spectroscope itself that has been improved for next year. With the improvements, we will have more students comment like this one, "my absolute favorite was building spectroscopes because I saw the colors that make up a light bulb.”

By far, the most important lesson learned was to have skilled presenters. The workshops which were rated the lowest by both teachers and students were presented by inexperienced presenters. The TRCC students not only practiced their lessons, but also practiced the hands-on portion of the workshop. As a result, we received these comments from students "We thought about what the college students taught us about laser engraving and creative inventions... maybe we can do that when we get older" and "It was nice that the TRCC students volunteered their time to work with us. They were very helpful." For the $5^{\text {th }}$ grade students, the common theme on their written year end evaluations was the workshops that were the best were the ones that they were highly engaged in using their creativity and they took something home. 


\section{ACKNOWLEDGEMENTS}

Audrey Aresco, Carole Fellenstein, Stephanie Gorman, $5^{\text {th }}$ grade science teachers and students, O'Connell School, East Hartford, CT

Judy Donnelly, professor of Optics and Fiber Optic Technology at Three Rivers Community College (TRCC), Norwich, CT

Kelly Everett and Cheryl Spencer, $5^{\text {th }}$ grade classroom teachers and students, Skinner Road School, Vernon, CT

Nora Jones, $5^{\text {th }}$ grade science teacher and students, GH Robertson, Coventry, CT

Making Waves: Optics and Acoustics EASTCONN Interdistrict grant program

Regional Center for Next Generation Manufacturing (RCNGM), supported by the Advanced Technological Education Program of the National Science Foundation NSF/DUE \#0903209 for additional funding of student workshops

SPIE Student Chapter, Three Rivers Community College, Norwich, CT

Spectroscope, What color is?, pinhole photography and polarization art were adapted from the PHOTON II Explorations in Optics projects of the New England Board of Higher Education, supported by the Advanced Technological Education Program of the National Science Foundation: PHOTON NSF/DUE \#0053284 and PHOTON2 NSF/DUE \#\#0302528

\section{REFERENCES}

[1] Frazier, R., Caemmerer, A., "Science + art = enhanced learning experiences for students," NSTA Science Scope January 2014, Volume 37, Number 5, 38-43.

[2] Project PHOTON: A Curriculum Development, Teacher Enhancement and Laboratory Development Project (\#ATE 0053284) and Project PHOTON2: Web-based Collaborative Learning for Teachers (\#ATE 0302528), projects of the New England Board of Higher Education, funded in part by the Advanced Technological Education program of the National Science Foundation.

[3] Carle, E., [Hello, Red Fox], Aladdin Paperbacks, New York, (2001).

[4] Albers, A., [Interaction of Color $50^{\text {th }}$ Anniversary Edition], Yale University Press, New Haven \& London (2013).

[5] Wing, N., [An Eye for Color The Story of Josef Albers], Henry Holt and Company, New York, (2009).

[6] "Next Generation Science Standards" http://www.nextgenscience.org.

[7]."Connecticut Pre-kindergarten-Grade 8 Science Curriculum Standards including Grade Level Expectations." Connecticut State Department of Education. Web. 01 July 2010. <http://www.sde.ct.gov>. 